\title{
JUAN JOSE ARREOLA: \\ LA FERIA O "UNA APOCALIPSIS DE BOLSILLO"
}

\author{
POR \\ CARMEN DE MORA VALCARCEL \\ Universidad de Sevilla, España
}

Concebida como ejercicio literario, La feria ${ }^{1}$ representa al mismo tiempo la imposibilidad de la escritura, y su estructura aparentemente desorganizada y caótica significa una renuncia al desarrollo discursivo propio de la retórica tradicional. Juan José Arreola consigna como escritor esa singularidad narrativa: "La feria pertenece al género de las apocalipsis de bolsillo y, por lo tanto, es natural que sus páginas recojan fragmentos, textuales o deformados, de la más variada tradición oral y escrita, procedente sobre todo de Ezequiel y de Isaías, de los Apócrifos, del cartulario colonial y de los anales de un pueblo imaginado al sur de Jalisco".

Cuando apareció esta obra Arreola contabilizaba ya unos cuantos éxitos en el mercado editorial: Varia invención (1949), Confabulario (1952) y Bestiario (1959), obras que en 1962 reuniría en un solo volumen titulado Confabulario total. Sus primeros tanteos fueron colaboraciones en las revistas Eos y Pan, de Guadalajara. Esta última agrupó a una promoción de escritores entre 1os que cuentan nombres importantes, como Arreola, Rulfo y Antonio Alatorre.

El nombre de Arreola suele ir asociado en México al de Juan Rulfo, quien, sin embargo, cuenta con un mayor reconocimiento por parte de la crítica literaria. E1 tándem Rulfo-Arreola tiene mucho que ver con la coincidencia entre su aparición y el auge literario de México, y con la circunstancia de que un grupo de amigos propicia el prestigio de su producción. Ambos se aproximan, además, por la voluntaria marginalidad con que han tratado de preservar su obra del mercado literario. Arreola no disimula la incomodidad ante el hecho de haberse beneficiado de la literatura, aun indirectamente, porque siente que se contamina un quehacer completamente auténtico y discreto, al volverse público.

\footnotetext{
' Juan José Arreola, La feria, México: Joaquín Mortiz, 1980, 6ª edic. Todas las citas de este artículo están tomadas de dicha edición.
} 
Si Arreola ha sido considerado como un escritor intelectualizado, de relatos preferentemente fantásticos, a despecho de otra vertiente más bien ligada a la vida rural, La feria representa un intento de calar en una corriente ya tradicional en la novelística mexicana desde la época de la Revolución como es el indigenismo. Sin embargo, nopodemos afirmar que $L$ a feria sea una novela indigenista stricto sensu; el autor no sólo no ha abandonado el estilo que le es propio, sino que -como afirma Emmanuel Carballo- esta novela "resume temática y estilísticamente la obra completa de Juan José Arreola"'.

La originalidad de La feria -que no la novedad- radica en la técnica narrativa: estructurada mediante un contrapunto de voces apenas deja un mínimo espacio para el narrador. Son los personajes los que hablan. Las voces se van contraponiendo unas a otras en forma de variaciones y la colectividad indígena soporta una parte considerable de este edificio musical.

Arreola no ofrece soluciones al problema del indio ni es su propósito como artista; se limita a testimoniarlo a través de las actitudes encontradas de sus personajes; desde el poderoso que reconoce las injusticias cometidas con el pueblo hasta el rico que, como Don Abigail, no vacila en recurrir a la extorsión con tal de encarcelar a 1os representantes de la Comunidad Indígena. La única salida posible parece ser la reclamación, ya milenaria, de unas tierras injustamente expropiadas.

¿Cuál sería entonces la aportación de Arreola en este sentido? El interés de La feria en el tratamiento del mundo indio resulta de su literaturización; como la voz popular se articula en la obra ya sea individualmente, a través de la figura patriarcal de Juan Tepano, o cn un coro innominado de voces como en las tragedias griegas. En esta novela, el nominalismo vale tanto como la misma realidad: "Repetir las palabras de los tlayanques - 1os desposeídos de la ticra_tiene para mí el valor de un alegato en favor de su causa"3 — ha confesado Arreola.

\section{DISCONTINUIDAD E INTEGRACION.}

Sin que podamos decir de ella que no es una novela, La feria atenta en gran medida contra los convencionalismos del género a los que - como lectoresestamos habituados.

En el nivel más superficial, la primera infracción afecta la tipografía: en lugar de ordenarse por capítulos se constituye a base de segmentos más o menos breves separados por indicadores procedentes del arte gráfico que representan

${ }^{2}$ Emmanuel Carballo, 19 protagonistas de la literatura mexicana del siglo XX, México: Empresas Editoriales, S/A/, 1965, p. 403.

${ }^{3}$ Ibidem, p. 406. 
simbólicamente el segmento que presiden. A veces, una sola palabra constituye por sí misma un segmento, por ejemplo, "iHojarascas!".

En otro orden de cosas, Arreola no presenta a sus personajes, de ahí la dificultad del lector para identificarlos a través del diálogo; tampoco precisa la dimensión temporal de los hechos, incluso prescinde fácilmente de su localización espacial.

En un nivel más profundo, observamos que la discontinuidad del discurso literario es una manifestación de la dialéctica vacío-plenitud, que en las obras modernas forma parte de su misma estructura. El título de uno de sus más importantes libros de relatos, Confabulario, de nuevo recogido en Confabulario personal, ya aludía a esa suerte de complicidad entre autor y lector, necesaria para que el proceso creador cierre su ciclo.

Paradójicamente, el orden fragmentario de La feria no implica incoherencia, antes bien remite a una movilidad infinitamente sensible de elementos cerrados. Asimismo, por las relaciones entre las distintas unidades compone un mosaico donde todas las piezas están perfectamente articulạdas. ¿No es posible concebir la composición de La feria sobre una maqueta previa? Utilizo el término "maqueta" en la acepción que emplea Barthes: "la maqueta no es una estructura completamente terminada ..., es más bien una estructura que se busca a partir de pedazos de hechos, pedazos que se trata de acercar, de alejar, de ensamblar, sin alterar su figura material; éste es el motivo de que la maqueta participe de éste arte del bricolage, al que Claude Lévi-Strauss acaba de dar una dignidad estructural (cn La pensée sauvage) 4

Arreola, al transformar incansablemente las unidades que componen su novela, mediante el doble proceso de segmentación y relación, las dota de sentido al tiempo que este se torna más transparente. Por su parte, el lector se siente invitado a recomponer pieza por pieza ese puzzle tan sabiamente desmontado. Puzzle de una pequeña población jalisciense, Zapotlán, de cuya historia pasada y presente pretende dar testimonio la novela. "Quise hacer - ha dicho Arreola- una especie de corte en la conciencia del pueblo, una especie de corte anatómico en el que apareciera la realidad caprichosamente fragmentada"s.

La significación cabal de las 289 unidades que comprende La feria sólo puede percibirse en cuanto somos capaces de integrarlas en sus micro-rclatos correspondientes; éstos, a su vez, se relacionan con otros, y así sucesivamente hasta integrar la unidad superior que es el relato.

\footnotetext{
${ }^{4}$ Roland Barthes, Ensayos críticos, Barcelona: Scix Barral, 1973, pp. $223-4$.

${ }^{5}$ Emmanuel Carballo, op. cit., p. 405.
} 
La coherencia de esta estructura depende en gran medida de la técnica de contrapunto que, a nivel de lenguaje, convierte La feria en una polifonía de voces. El sentido no está en cada uno de los micro-relatos sino en lo que se dicen entre ellos: frases, fragmentos y voces que se transforman en réplicas unas de otras. Por ejemplo, en uno de 1 os apuntes de un zapatero-agricultor se dice del chicalote: "En toda la región se recogen de quinientas a seiscientas toneladas de esta oleaginosa silvestre, que alivia en su tiempo la miseria de las clases menesterosas ..." (p. 13). En el segmento siguiente responde una voz: "-Alivia, „madre! Este hombre no sabe lo que dice. En todo caso aliviaba, porque el chicalote se está acabando en Zapotlán, como el tule de la laguna ... Vayan a ver: ¿dónde está el tule? ¿Dónde está el chicalote? Y es que el año pasado, del hambre que teníamos, no dejamos nada para semilla ..." (p. 11).

Este caos aparente, magnificamente estructurado por el escrito se va organizando en líneas definidas a medida que encontramos 1 os ejes interiores que sustentan la narración. Estos son fundamentalmente dos: el problema de la tierra y la devoción a San José, Patrón de Zapotlán. En ellos se articulan otros temas subsidiarios hasta completar la visión moral, social, económica, religiosa, etc., del pueblo.

\section{EL PROBLEMA DE LA TIERRA}

Con este tema reanuda Arreola un elemento referencial que había encontrado su expresión en la novela de la Revolución mexicana y que, curiosamente, aparece con anterioridad en dos cuentos suyos "El cuervero" (Varia invención) y "Corrido" (Bestiario).

Desde su primera página, el clima de la novela apunta en esa dirección:

Somos más o menos treinta mil. Unos dicen que más, otros que menos. Somos treinta mil desde siempre. Desde que Fray Juan de Padilla vino a enseñamos el catecismo, cuando Don Alonso de Avalos dejó temblando estas tierras. Fray Juan era buena gente y andaba de aquí para allá vestido de franciscano, con la ropa hecha garros, levantando cruces y capillitas. Vio que nos gustaba mucho danzar y cantar, y mandó traer a Juan Montes para que nos enseñara la música. Nos quiso mucho a nosotros los de Tlayolan. Pero le fue mal y dizque lo mataron. Dicen que aquí, dicen que allá. Si fue en Tuxpan, lo hicieron cuachala. Si fue aquí, nos lo comimos en pozole. Mentiras. Lo mataron en Cibola a flechazos. Sea por Dios. Antes la ticrra era de nosotros los naturales. Ahora es de las gentes de razón. La cosa viene de lejos. Desde que los de la Santa Inquisición se llevaron de aquí a don Francisco de Sayavedra, porque puso su Iglesia aparte en la Cofradía del Rosario y dijo que no les quitaran la tierra a los tlayacanques. Unos dicen que lo 
quemaron. Otros que nomás lo vistieron de judas y le dicron azotes. Sea por Dios. Lo cicrto es que la tierra ya no es de nosotros y allá cada y cuando nos acordamos. Sacamos los papeles antiguos y seguimos dale y dale. Señor Oidor, Señor Gobernador del Estado, Señor Obispo, Señor Capitán General. Señor Virrey de la Nueva España, Señor Presidente de la República ... Soy Juan Tepano, el más viejo de 1os tlayacanques, para servir a usted: nos lo quitaron todo ... (pp. 7-8).

Según palabras del propio Arreola, este pasaje "condensa el espíritu del libro". Y no sólo por la voz directa y populär de Juan Tepano, sino por el tema que, a modo de obertura, nos introduce en LaFeria. Un dilatado sustrato histórico ha conducido al pueblo al estado de marginación en que se halla. La representación de este proceso podría ser la siguiente:

\section{PASADO REMOTO}

a) Epoca virreinal. Origen del problema: el Rey mandó dividir Zapotlán en cinco comunidades indígenas, cada una con su tlayacan que, y los frailes las convirtieron en Cofradías, cada una con su santo y su capillita.

b) Leyes de Reforma (1859), Benito Juárez. Ley de Desamortización de los bienes civiles y cclesiásticos: al ponerse en venta estas tierras los bienes fueron adquiridos por los que tenían capital, que eran los que tenían también bienes, lo cual los hizo más ricos todavía. Desde entonces data el verdadero pleito de los indios.

\section{PASADO CERCANO}

Período prerrevolucionario: Porfirio Díaz. Los ricos invertían en tierras y las acaparaban sin escrúpulos, y gracias a las leyes de baldíos de 1893 y 1894 los grandes latifundios crecieron aún más. 1902: "el famoso reparto" que fue el fraude más grande y vergonzoso que registra la historia del pueblo.

\section{PASADO INMEDIATO}

1909: paralización del pleito como consecuencia de la revuelta.

Përíodo revolucionario: la Revolución dejó parado el pleito, pero el pueblo no cesa en sus reclamaciones: "a nosotros no se nos olvida, y cada que podemos, sacamos los papeles, los antiguos y los nuevos que dicen siempre lo mismo: que tenemos razón y que somos dueños de la tierra" (p. 29). 
Estos antecedentes históricos fundamentan la actuación de los dos grandes antagonistas del relato: opresores vs. oprimidos, al tiempo que proporcionan información sobre ciertas condiciones que determinan el "modus vivendi" de Zapotlán y de muchos otros pueblos mexicanos: una gran masa de desposeídos frente a una minoría que controla y dirige sus vidas.

La lógica de las acciones, en este caso, estaria representada por una secuencia compleja del tipo denominado por Brémond "por enclave":

\section{MEJORAMIENTO A OBTENER}

Los indios, injustamente desposeídos

de sus tierras, recurren a procedimientos

legales para recuperarlas

\section{PROCESO DE MEJORAMIENTO}

La intervención del Sr. Farias y su ayuda económica para costear los pleitos hacen concebir esperanzas a los indios para la posible solución de sus problemas = DEGRADACION POSIBLE

Reacción negativa de los propietarios de Zapotlán.

\section{PROCESO DE DEGRADACION}

1. Don Abigail recurre a la extorsión para acusar a los indígenas de ser los autores de unos anónimos que circulaban por el pueblo.

2. Carta a las autoridades eclesiásticas acusando a los indios y al párroco de disponer del dinero que se recauda en sus sectores para costear los gastos del pleito y no para los festejos religiosos.

\section{MEJORAMIENTO NO OBTENIDO = DEGRADACION CUMPLIDA Nueva paralización de los pleitos: "-Y las tierras ¿se las van a devolver a los indios? -El año de la hebra y el mes del cordón" (p. 180-181).}

Si el problema de la tierra constituye uno de los ejes estructuradores de $L a$ feria, existe, en relación con él, una historia menor que atraviesa la novela de parte a parte: la experiencia del zapatero que quiso ser agricultor. El engaste entre las 
dos historias se produce mediante la técnica de contrapunto, aunque, desde luego, de forma atenuada. El tercer segmento de la novela corresponde ya a los apuntes del zapatero-agricultor: " $Y$ Ya soy agricultor! Acabo de comprar una parcela de cincuenta y cuatro hectáreas de tierra inafectables en un fraccionamiento de la Hacienda de Huescalapa ... Esta aventura agrícola no deja de ser arriesgada, porque en la familia nunca ha habido gente de campo. Todos hemos sido zapateros ... Junto a mi libro de cuentas agrícolas, que estoy llevando con todo detalle, se me ocurrió hacer estos apuntes ...

Lo único que me ha extrañado un poco es que para la operación de compraventa han tenido que hacerse toda una serie de trámites notariales muy fastidiosos. El legajo de las escrituras es muy extenso. Tal parece que esta tierra, antes de llegar a las mías, ha pasado por muchas otras manos". (pp. 8-9)

A continuación, un texto perteneciente al cartulario virreinal sirve de contrapunto al segmento citado sin que, naturalmente, se refiera a él: "Denuncio a Vuestra Majestad las mil maldades y las mil ventas y reventas de que son objeto estas tierras. Y es que un oficial barbero, herrero, zapatero y otros hombres viles que no son labradores, teniendo amistad con uno de vuestros oidores e visorreyes, obtienen luego con seis testigos de manga beneficio de tierras ..." (p. 9).

El proceso de la historia que comentamos discurre de modo similar a la anterior:

\section{DESEO SER AGRICULTOR}

Compra de tierras en Tamaco y

arriendo de un potrero en Tiachepa.

\section{MEDIOS PARA LA ACCION}

- Sistema de contratación de peones

-labores agrícolas

-fin de las faenas

\section{DEGRADACION POSIBLE}

- La falta de lluvias en Tiachepa le ocasiona pérdidas.

- Como un mal presagio, entre los olotes aparece un tecolote, "caricatura de fruto" o "mueca del mal".

\section{PROCESO DE DEGRADACION:}

Los problemas se intensifican por la aparición de plantas cizañeras.

- Los costos aumentan.

-El negocio de la zapatería decae por el abandono de su ducño. 
-Peligro a causa de las reivindicaciones de los indios.

-El terreno de Tacamo estaba en litigio entre dos hermanos y el que se lo había vendido no era dueño de todo.

DESEO NO LOGRADO = DEGRADACION CUMPLIDA

Vuelve al negocio de la zapatería y abandona el de la agricultura.

La piedra de toque de esta experiencia radica en la perspectiva irónica y humorística adoptada por el autor, despojándola así de todo dramatismo "Vuelvo a mis zapatos - nos dice el agricultor en su último apunte-. Por cierto que lo unnico positivo que saqué de esta aventura es la ocurrencia de un modelo de calzado campestre que pienso lanzar al mercado para sustituir a 1os guaraches tradicionales. A ver si tengo éxito y puedo pagar pronto la hipoteca de la casa" (p. 165).

La aventura en sí es una extensa perífrasis del popular "zapatero a tus zapatos". ¿Acaso no estamos ante un fenómeno de intratextualidad en el sentido manejado por Severo Sarduy? ${ }^{6}$.

Puesto que La feria representa en gran medida la recuperación del lenguaje popular, nada más acorde que incorporar sus dichos y refranes, conscientemente o no. Pero si en la época estudiada por Sarduy -el barroco- la intratextualidad resultaba en muchos casos una consecuencia de la represión, en el caso de La Feria se trata más bien de una expansión. De un divertimento y de una conciencia literaria. Introducir el tópico o refrán en el texto literario -en nuestro casoresultaría redundante; dejarlo entrever mediante la ironía y el chiste convierte al lector en cómplice.

En otro sentido, la inserción de este relato secundario produce lo que Jean Bellemin-Noël denomina "effet de miroir": "un réçit second, de dimensions réduites, se trouve enchâssé dans le réçit premier, et il répète "en petit", comme emblematiquement, ce qui se passe dans l'aventure principale"?

El propósito de convertirse en agricultor, los esfuerzos prodigados para sacar adelante las tierras, las eventualidades que van surgiendo y el fracaso final, guardan

\footnotetext{
"Cfr. Severo Sarduy, "El barroco y el neobarroco", en América Latina en su literatura,

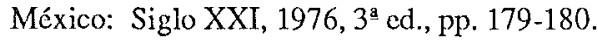

${ }^{7}$ Jean Bellemin-Noël, "Notes sur le fantastique", en Littérature, Paris, nº 8, diciembre 1972, p. 20.
} 
una evidente relación de analogía con el proceso de las reclamaciones de los indios.

\section{LA DEVOCION A "SEÑOR SAN JOSE" O LA FERIA}

Para comprender la dimensión exacta que posee para el pucblo de Zapotlán la celebración de la fiesta anual —en el mes de octubre—en honor de su Patrón, es preciso recurrir al testimonio de aquellos que han reflexionado sobre el ser de México y los mexicanos. Octavio Paz en El laberinto de la soledad ofrece una visión lúcida del tema:

El solitariomexicano ama las fiestas y las reuniones públicas. ... Somos un pueblo
ritual ... En pocos lugares del mundo se puede vivir un espectáculo parecido al
de las grandes fiestas religiosas de México, con sus colores violentos, agrios y
puros, sus danzas, ceremonias, fuegos de artificio, trajes insólitos y la inagotable
cascada de sorpresas de los frutos, dulces y objetos que se venden esos días cn
plazas y mercados... Nuestra pobreza puede medirse por el número y suntuosidad
de las fiestas populares

Arreola, para hablar de Zapotlán, ha reunido a todo el pueblo en el único acontecimiento aglutinador por encima de las diferencias sociales, religiosas o morales: la fiesta anual.

En las primeras páginas de la novela nos explica el origen del culto recurriendo a la parodia por analogía con 1os Evangelios: "Señor San José llegó a Zapotlán de un modo muy humilde y muy misterioso. Acompañado por la Virgen y a lomo de una mula" (p. 16). E1 comienzo ex-abrupto desconcierta al lector y lo desarma por hallarse asociados Zapotlán, San José y la Virgen. Unas frases más adelante, sabemos que se trataba de unas imágenes transportadas en una mula por un arriero que llegó al pueblo en 1745 y murió dejando alli la acćmila y la carga. Dos años más tarde es proclamado Patrón contra los terremotos, tan frecuentes en esta zona.

El desarrollo de esta historia principal arrastra consigo varios subtemas:

1. - Medios para la celebración de la feria:

-obtención de dinero por la persona nombrada para cllo. (mayordomo). Muerto el Mayordomo nombrado para este año (El Licenciado), todo el pueblo de Zapotlán será mayordomo y costeará los gastos.

\footnotetext{
${ }^{8}$ Octavio Paz, El laberinto de la soledad, México: FCE, 1980, $8^{\text {a }}$ reimpresión, p. 42.
} 
En este punto se produce una intersección entre las dos historias mayores de la novela: el problema de la tierra y la devoción a San José. Los indios, al tener que ahorrar para los gastos de La feria cuentan con menos dinero para costear sus pleitos. Mientras el párroco les aconseja que no se propasen en los gastos, el rico Don Abigail no oculta su satisfacción.

2. - Organización y actividades:

El castillo

La Coronación Pontificia de San José

El reparto de décimas

Los juegos florales

Las danzas

Festejos profanos (corridas de toros)

El desfile de las Andas

3. - El fracaso final de La feria a cargo de una banda de desalmados.

El tema de la devoción a San José se bifurca en diversos episodios:

A) La muerte del Licenciado. Este agente del que sólo tenemos referencia por las voces de otros personajes, se caracteriza por tres rasgos: ser el más rico, ser el prestamista oficial (usurero), ser mayordomo de la Feria. Su muerte repentina frustra las esperanzas de contar con su dinero para costear la Función tal como ćl había prometido:

"- Y la Función, quien la va a hacer ahora?

-Pues eso va a estar difícil porque murió intestado, y su hermano, se lo digo aquí en confianza, no le da agua ni al gallo de la Pasión ..." (p. 54)

Al no contar con el Licenciado se permitc a los indios ser mayordomos para cubrir los gastos de la Función.

B) El terremoto. Guarda cierto parentesco con el anterior. Uno y otro se producen a las doce, y, sin embargo, en ambas ocasiones el campanero había dado trece campanadas, símbolo de un mal presagio. Dentro del pánico general, un grupo de vecinos reacciona y " sin decir palabra, se subieron al altar y bajaron la imagen de Señor San José en hombros a la plaza.

Una gran multitud se les unió, entre lágrimas y gritos, y comenzó la procesión de amargura por todas las calles del pueblo" (p. 31)

El episodio conecta con el origen del nombramiento de San José como Patrón para 1os terremotos. Desde el punto de vista narrativo posee el valor de un hecho 
apocalíptico, un castigo por "los muchos pecados" de la población. El entierro del licenciado estuvo acompañado por una lluvia torrencial; después del terremoto la naturaleza quedó paralizada; los fenómenos atmosféricos también forman parte de la parodia bíblica del autor.

C) La devoción entendida exclusivamente para el provecho propio está ejemplificada en la anécdota de Don Faustino, el Presidente, que habla de tú a San José y perdió la devoción porque no atendió sus rezos una vez que se encontraba en apuros.

D) Confundir la magnitud de la devoción con cl tamaño de la vela que se le coloca al Santo, es el caso de María Palomino. El efecto producido es el de lo fantástico por hipérbole, procedimiento con el que Arreola está más que familiarizado por su proclividad kafkiana. La reducción al absurdo de una situación planteada "in initio" como normal aparecía ya en sus cuentos: la compra de una vela llega a convertirse en el encargo de una especie de poste de cera que costaba 200 pesos y pesaba 20 arrobas.

El episodio de la vela se relaciona con la seducción de Chayo, hija de Don Fidencio, por Odilón, hijo de Don Abigail. El humor se producía en el primer caso en virtud de la tensión entre el celo de Don Fidencio por su cera - que cuidaba con verdadero mimo - y el manoseo vehemente de la compradora. Cuando Chayo queda desgraciada, el vendedor cede precisamente en lo que más le dolía: "Al día siguiente mostró al mundo otra cara, transfigurada por la injusticia. Puso sobre el mostrador tơla su existencia de velas de cera blanca y dejó que las gentes del pueblo las manosearan a su antojo, les clavaran las uñas y se fueran sin comprarlas ..." (p. 155).

No faltan los típicos casos de venganza y machismo; escenas de sangre y cuchillos. "En ocasiones - reconoce Octavio Paz-, es cierto, la alegría acaba mal: hay riñas, injurias, balazos, cuchilladas. También eso forma parte de la fiesta ... Todos están poseídos por la violencia y el frenesi"”.

El último segmento textual de la novela coincide con el final de La feria a cargo de una banda de desalmados. Cuando iba a darse la orden de encender el inmenso castillo pirotécnico, unos enmascarados "bañaron de petróleo la base de las cuatro torres que sostenían la plataforma desde donde se alzaba el castillo principal, y les prendieron fuego ... Una hora después, no quiedaba más que un montón de brasas y pavesas, entre las que de vez en cuando tronaba todavía algún cohete retardado ... Ya para venirme, me volví por última vez y vi desde lejos el escenario. En el lugar donde estaba el castillo, vi subir al cielo la última columna de humo, recta y delgada." (pp. 182-183)

Ibidem, p. 44. 
Pasaje revelador: en él coinciden el final de la feria y el final de la novela, identificación nada gratuita en un autor como Arreola. La feria como tema de la novela es la novela como feria. Artificio hábilmente montado por el escritor donde los personajes son titeres que hablan por un instante desde su pequeño drama intimo para desaparecer y dejar paso a otras muchas criaturas. El sincretismo, la variación, la pluralidad de tonos y de voces, el contrapunto verbal, son otras tantas vertientes de la escritura lúdica y festiva de La feria.

Precisamente, refiriéndose a la idea motriz de la novela ha dicho Arreola: "En un principio tenía el propósito de rendir homenaje a mi pueblo, al que amo tanto, pero a la hora de escribir volvió a triunfar en mí, no sé por qué artes, el espíritu irónico y sarcástico - que ya se había adueñado de casi todas las páginas de Confabulario. $\mathrm{Y}$ de las personas hice marionetas, monigotes entregados a una danza entre macabra y grotesca" 10 .

Hasta ahora, en todas las historias estudiadas cabe encontrar al menos un punto de intersección: el fracaso. Tanto las reivindicaciones de los indios, como la aventura del zapatero-agricultor y la misma feria desembocan en otras tantas frustraciones.

\section{EL ESPECTRO DE LA REALIDAD}

La feria alberga en su estructura fragmentada un panel con todos los registros posibles de la realidad zapotlense. Este plano de objetividad abarca: espacio, sociedad, moral, usos y costumbres, cultura y supersticiones.

La circularidad, la redondez es la nota que define el ámbito espacial en $L a$ Feria. En una descripción de intenso lirismo - no en balde Arreola ha sido incluido en la Antología Poesía en movimiento - el autor mexicano, por boca de un personaje innominado, nos descubre el asombro ante la que fuera su primera revelación del paisaje de Zapollán: "Campo de Zapotlán, mojado por la lluvia de junio, llanura lineal de surcos innumerables. Tierra de pan humilde y de trabajo sencillo, tierra de hombres que giran en la ronda anual de las estaciones, que repasan su vida como un libro de horas y que orientan sus designios en las fases cambiantes de la luna. Zapotlán, tierra extendida y redonda, limitada por el suave declive de los montes, que sube por laderas y barrancos a perderse donde empieza cl apogeo de los pinos. Tierra donde hay una laguna soñada que se disipa en la aurora. Una laguna infantil como un recuerdo que aparece y se pierde, llevándose sus juncos y sus verdes riberas ... (p. 58).

\footnotetext{
${ }^{10}$ Emmanuel Carballo, op. cit., p. 405.
} 
Así los habitantes de Zapotlán dejạn rodar sus vidas en una monotonía cíclica que imita la propia monotonía de la Naturaleza.

La sociedad se encuentra estratificada en la aristocracia lugareña -intelectual y económica-, el clero, la clase media y la clase rural. Cuando muere uno de los miembros de la clase superior - como el Licenciado- inmediatamente es sustituido por otro (Don Abigail).

El sistema económico semi-feudal no afecta exclusivamente a la oposición entre las capas sociales más alejadas, también repercute, en el plano moral, en una mayor proclividad a la represión y a la polaridad de las conductas, entre la prohibición y la permisión.

1. Del lado de la prohibición pueden interpretarse 1os siguientes episodios: las confesiones de un joven aprendiz de imprenta atormentado por el despertar de la sexualidad; Paulina, la madre soltera que se envenena con estricnina; el hundimiento moral de Don Fidencio cuando sabe que su hija Chayo ha sido seducida; y la madre que obstaculiza la vida marital de su hija. Todos ellos caen dentro de un puritanismo mal entendido.

2. En contraposición, del lado de la permisión y de la violación, recordemos los frecuentes casos de adulterio ("Hojarascas" y "Pedazo de hombre"), el donjuanismo de Odilón, así como el reconocimiento oficial de una "zona de tolerancia" en las afueras del pueblo para ejercer la prostitución.

Estas dos actitudes divergentes confluyen en una curiosa costumbre, a mitad de camino entre lo serio y lo cómico: cuando muere una "mujer de la vida alegre ... una o dos de sus compañeras, o la dueña de la casa en que pecaba, salen a pedir cl vestido de una muchacha honrada para vestirla con ropa limpia" (p. 153).

La ironía del autor luce sus mejores galas en las sesiones culturales del Ateneo, donde, bajo la presidencia de Don Alfonso, se reúnen los "amantes de las letras" para un intercambio cultural con poetas y escritores de laregión. Quizá por ser éste uno de los temas que más le duelen a Arreola -el uso y abuso de la cultura cuando se hace oficial- la reducción a lo grotesco alcance en él una lúcida perfección.

\section{LA ESCRITURA DE LA FERIA}

La expresión "Apocalipsis de bolsillo" con que Arreola ha definido su novela se refiere tanto a la heterogeneidad de su escritura, como a la intertextualidad bíblica de su composición y al fatalismo -mediatizado por la ironía y el sarcasmo- de 1os sucesos contados: la historia de Zapotlán es una cadena de desengaños, frustraciones y premoniciones apocalípticas, como el terremoto, que culminan en el derrumbamiento del gigantesco castillo pirotécnico. 
El autor ha recurrido a la sustitución de la narración por el diálogo ya directo, ya como soporte de un fragmento narrativo- interferido por un collage de textos de diversa índole, inyectándole así a su prosa dinamismo, vivacidad y justeza.

Lo importante de La feria - ya lo dijimos al principio- es la ósmosis entre el lenguaje coloquial de la gente de Zapotlán, que Arreola ha sabido rescatar con toda naturalidad, y el tex to literario. Ahora bien, el collage aquí, más que un juego experimental, obedece a la necesidad de ajustar la técnica a la diversidad de temas y personajes que convierten la obra en un coro de historias disímiles, en un careo de voces contrapuestas hasta configurarse en una totalidad.

Por ello, a nivel verbal podemos distinguir dos aspectos: material no creado por el autor y patrones rítmicos:

\section{Material no creado por el autor.}

En este punto, la intertextualidad es utilizada con distintos fines y se emplean procedimientos como la imitación, la parodia, la cita, ctc.,

La interpolación de códigos aliterarios procedentes de 1os anales del pueblo, que corresponden a distintos momentos de su historia, las reivindicaciones de $10 \mathrm{~s}$ indios formuladas por escrito, informes de algún visitador, el certificado del nombramiento de Patrón, etc., proporcionan un trasfondo histórico a los hechos actuales.

Otros textos están tomados de la Biblia, de Isaías, Ezcquiel y 1os Apócrifos, comoel propio Arreola ha explicado. A modo de ejemplo, recordemos el segmento en que se cita un pasaje de Isaías; el autor, para facilitar, quizá, la identificación del texto, da al personaje que habla ese mismo nombre:

-"Bueno, en resumidas cuentas, esto no es ninguna novedad. La Función siempre la ha hecho el pueblo, aunque haya Mayordomo. ¿De dónde han sacado los ricos su dinero? "... Habéis devorado la cosecha, y del despojo de los pobres están llenas vuestras casas". Y yo no soy quien lo dice ...

-Ah qué usted, don Isaías ..." (pp. 57-58)

2. Patrones rítmicos.

Desde el punto de vista formal, La feria es una novela cambiante que acoge una multiplicidad de escrituras para "convocar el mito de la plenitud oral"-como afirma Julio Ortega ${ }^{11}$. Para cada tema un tono distinto y, en el fondo, el diálogo. En él se afirma el pulso dramático de esta obra aquilatado siempre por la ironía. Sin duda la formación teatral de Arreola como autor dramático y su experiencia escénica como actor gravita sobre la novela.

\footnotetext{
${ }^{11}$ Julio Ortega, La contemplación y la fiesta, Venezuela: Monteávila, 1969, p. 54.
} 
La gran variedad de patrones rítmicos confieren a esta obra un carácter marcadamente sinfónico.

a) Apuntes del zapatero-agricultor: como escritura está plagada de términos relativos al campo semántico de la agricultura en un ingenuo alarde tecnicista. Lo humorístico resulta del dislate entre la teoría y la práctica. E1 tono ya había sido ensayado en un cuento de Varia invención: "Hizo el bien mientras vivió".

b) El diario de un joven enamorado que cuenta la fluctuación de sus relaciones con María Elena.

c) La escritura como exorcismo de ciertas obsesiones, de tipo sexual, en este caso, es el motivo del cuento "Pitirre en el jardín", basado en la Alicia ... de Carroll.

d) Aunque son varios los segmentos dedicados a las confesiones del aprendiz de imprenta, esta manifestación verbal se desborda en una prosa electrizante cuando, a raiz del terremoto, todos los habitantes del pueblo, aterrorizados, sienten necesidad de confesarse. Todas las confesiones se simultánean, sin transición, en una sola, logrando el lenguaje una velocidad vertiginosa.

e) Cartas, anónimos que perturban la vida de los zapotlenses y que son utilizados por algunos para sus propios fines.

f) Canciones populares sobre la Revolución, burlescas, coplas malintencionadas que provocan un nerviosismo enfermizo en el pueblo.

g) La parodia cuenta con dos ejemplos notables aunque de signo diferente. El primero corresponde a la historia del torero Pedro Corrales y Concha de Fierro la atracción del prostíbulo porque nadie había logrado hacerle perder su virginidad. Cuando el torero lo consigue, la escena se describe mediante una trasposición del léxico taurino al lance amoroso.

El segundo constituye uno de los mejores momentos de la obra en la utilización de la clave paródica. El éxito radica en el estilo con que un socio del Ateneo describe las sesiones culturales con la retórica mesurada y provinciana, los alardes metafóricos y la sucesión de tópicos en un lenguaje pretendidamente elevado:

\footnotetext{
Muy buena idea la de Don Alfonso: nuestro Ateneo, que tan grato pasatiempo nos proporciona la noche del jueves de cada semana, es un islote incomunicado en este archipiélago del sur de Jalisco. No sabemos nada de aquellos que tan cerca de nosotros cultivan las letras en sus rincones de provincia. Apenas si de vez en cuando algún periódico local nos da muestras de esos ingenios escondidos ... (p. 100).
}

Otro apartado importante quedaría integrado por episodios pertenecientes al género de la literatura fantástica y del "realismo mágico".

El realismo fantástico de filiación kafkiana se produce en la escena entre Don Fidencio y María Palomino. La figura retórica sirve de catalizador: la simple 
compra de una vela se convierte, en virtud de la hipérbole, en una acción complicada, hasta el absurdo.

Emparentadas con el realismo mágico otras dos historias: la de Gallina Sin Pico y la del origen de Zapotlán, o por qué los indios deben respetar a los cuervos.

El perspectivismo y lo maravilloso se asocian en un segmento cuya primera parte imita la escritura de la Biblia:

Y yo, José, me eché a andar, pero casi no avanzaba entre aquel mar de gente. $\mathrm{Y}$ al elevar mis ojos al espacio, me pareció ver como si el aire estuviera estremecido de asombro. Y cuando fijé mi vista en el firmamento, lo encontré estático y los pájaros del cielo inmóviles - y al dirigir la mirada hacia la tierra, vi un recipiente en el suelo y unos trabajadores del campo echados en actitud de comer, con sus manos en la vasija. Pero los que simulaban masticar, en realidad no masticaban, y los que parecían en actitud de tomar la comida, tampoco la sacaban del plato, y finalmente, los que parecían introducir los manjares en su boca, no lo hacían, sino que tenían sus rostros mirando hacia arriba. También ví unas reses que iban siendo arreadas, pero no daban paso, y el que las llevaba levantó su diestra y se quedó con la mano tendida en el aire. Y al pasar por un aguaje ví unos bueyes que ponían en el agua sus hocicos pero no bebían. En una palabra, todas las cosas fueron apartadas de su curso normal" (pp. 81-82).

A continuación, dentro del mismo segmento una voz en tercera persona ofrece su punto de vista sobre los mismos hechos, desvelando así la extrañeza del fragmento anterior.

Este proceso de humanización de una imagen religiosa fucra de su contexto histórico, como cl caso de San José en La feria, ha sido lúcidamente tratado por Aguilera Malta en Siete lunas y siete serpientes, al convertir la imagen de Jesús crucificado en un personaje más de la novela.

El Arreola de Laferia no se muestra exclusivamente comoel escritor que toma distancia mediante la alquimia verbal y la ironía para crear un clima de "confabulación" con el lector. Decir que la novela se refiere a su pueblo natal es tanto como afirmar su carácter autobiográfico dentro de la ficción.

Sin contarnos su vida, quiere descubrirse a sí mismo, y en esa búsqueda la realidad de Zapotlán o de Ciudad Guzmán le tienta, porque, como ha dicho Octavio Paz, "El hombre nunca es él enteramente, siempre inacabado, sólo se completa cuando sale de sí mismo y se inventa". Su obra, en este sentido, es el resultado de una invención literaria, pero también de una necesidad psicológica: la necesidad -según sus propias palabras - de "cumplir con ciertas voces que no querían apagarse en mi y también darle salida a lo que soy debajo del literato aparente ... 
el niño afligido por el drama de la conciencia y del erotismo que despierta y que en mí no ha acabado de abrir los ojos".

¿Acaso no era ése el drama de otro mexicano genial que cantó la provincia, aquel instalado bajo el doble signo del león y la virgen? Tendríamos que preguntarnos si Arreola al reinventar la provincia en La feria se ha encontrado con López Velarde o ha sido la provincia de López Velarde la que ha inventado a Arreola. Como su antecesor, ha sabido rescatar con la mirada del asombro infantil una realidad que esperaba ser salvada.

Finalmente, si La feria en su fragmentación es la experiencia de la escritura como desencanto, en cambio, se aparta del lenguaje literario para reconciliarse con la realidad a través de la recuperación del lenguaje visceral e instintivo del diálogo. 
